\title{
Rapid Screening of Volatile Organic Compounds from Aframomum danielli Seeds Using Headspace Solid Phase Microextraction Coupled to Gas Chromatography Mass Spectrometry
}

\author{
Mosotho J. George (iD, ${ }^{1,2}$ Patrick B. Njobeh, ${ }^{3}$ Sefater Gbashi, ${ }^{3}$ Gabriel O. Adegoke, ${ }^{3,4}$ \\ Ian A. Dubery, ${ }^{2}$ and Ntakadzeni E. Madala $\mathbb{i D}^{2}$ \\ ${ }^{1}$ Department of Chemistry and Chemical Technology, National University of Lesotho, Roma 180, Lesotho \\ ${ }^{2}$ Department of Biochemistry, University of Johannesburg, P.O. Box 524, Auckland Park 2006, South Africa \\ ${ }^{3}$ Department of Biotechnology and Food Technology, University of Johannesburg, Doornfontein Campus, P.O. Box 17011, \\ Johannesburg 2028, South Africa \\ ${ }^{4}$ Department of Food Technology, University of Ibadan, Ibadan, Nigeria
}

Correspondence should be addressed to Mosotho J. George; jm.george@nul.ls

Received 20 December 2017; Accepted 13 March 2018; Published 19 April 2018

Academic Editor: Jan Åke Jönsson

Copyright (C) 2018 Mosotho J. George et al. This is an open access article distributed under the Creative Commons Attribution License, which permits unrestricted use, distribution, and reproduction in any medium, provided the original work is properly cited.

Volatile organic compounds (VOCs) derived from plants have been used in the fragrance industry since time immemorial. Herein we report on the rapid screening of VOCs from seeds of ripe Aframomum danielli (family, Zingiberaceae) using a polydimethylsiloxane fibre headspace solid phase microextraction coupled to a gas chromatography mass spectrometry (SPMEGC/MS) instrument. Portions of $0.25,0.35$, and $0.50 \mathrm{~g}$ of ground sample were weighed and extraction of volatile organic compounds (VOCs) was achieved using a $100 \mu \mathrm{m}$ polydimethylsiloxane solid phase microextraction (PDMS SPME) fibre, with the equilibrium time of 40 minutes and extraction temperature of $50^{\circ} \mathrm{C}$; the following compounds with their respective relative abundances were obtained as the top ten most abundant and annotated ones using NIST, Wiley, and Fragrances Libraries: eucalyptol (58\%); $\beta$-pinene (22\%); $\alpha$-pinene (7.5\%); $\alpha$-terpineol (4\%), $\alpha$-terpinyl acetate (2\%); $\alpha$-bergamotene (1\%); pinocarveol $(0.39 \%) ; \alpha$-copaene $(0.35 \%)$; caryophyllene (0.34); and $\beta$-bisabolene $(0.31 \%)$. These compounds have been reported elsewhere in the literature and listed in the Fragrances Library, incorporated into the Saturn QP2020 GCMS Solution ${ }^{\circledR}$ software used for their analysis.

\section{Introduction}

Plants have always been part of human life where they do serve as food source not only for humans but for animals as well. There are a number of benefits that can be derived from plants other than nutritional value. Many different plants have been used in traditional medicine since time immemorial. With the increasing frequency of degenerative diseases occurrence, wild plants that have been traditionally ignored are now receiving considerable attention owing to their potential in antioxidant activity and other medical benefits thereof. As such, there is much curiosity in understanding the phytochemical composition and chemical characteristics of these herbal plants.

Aframomum danielli, a plant that grows widely in West Africa, is an underutilized plant species known to contain an enormous variety of interesting phytochemicals [1-3]. There are a number of reports where the Aframomum species demonstrated some medicinal effects such as anticancer, antiplasmodial, antiulcer, antimicrobial [4], and antifungal [5]. This plant can also act as food preservative when added to packaged foods [6]. For example, it improved the postharvest storage shelf-life of tomato [7] and has been found to stabilise the refined peanut oil more effectively than 
the synthetic antioxidants such as butylated hydroxytoluene and $\alpha$-tocopherol [1]. Although different parts of this plant (flower, leaf, stem, root, and seeds) have been investigated [2, $3,8]$, the seeds in particular have demonstrated very potent pharmacoactive and sensory (flavour) properties [8-10]. The seeds of $A$. danielli are smooth, shiny, and olive brown in colour [11] and upon crushing produce a very strong aromatic smell that resembles eucalyptus leaves, which suggests an abundance of VOCs and essential oils such as those found in Eucalyptus trees. Essentially, the main chemical classes of VOCs produced by plants include terpenoids, benzenoids and phenylpropanoids, alkanes, alkenes, alcohols, esters, and various derivatives of fatty acids and amino acids [12, 13].

Essentially, VOCs from plant sources are widely used in the pharmaceutical, antiseptic, flavouring, fragrance, and other cosmetic and pharmacological industries, and their analysis has been well established [14-17]. Solvent extraction and hydrodistillation are the two major conventional ways to extract VOCs from plants [17], although various other extraction methods for VOCs in different plant matrices have been reviewed in literature [17, 18]. However, there are eminent disadvantages associated with these methods, such as low recovery, destruction of sample matrix, and use of nonenvironmentally friendly organic solvents [17, 19]. Headspace solid phase microextraction (HS-SPME) is a solvent-free, nondestructive, and easy approach for collecting VOCs emitted from plants $[20,21]$. This approach can be practiced even using live plants without harvesting them. Moreover, HS-SPME coupled with gas chromatography (GC) has been shown to be very efficacious, collecting considerable amounts of volatile compounds [21-24].

Herein we report the development of a screening method for VOCs using HS-SPME-GC-MS analysis from the crushed ripe seeds of $A$. danielli with the view of using some of these volatiles for possible agricultural and pharmacological applications. Different parameters, namely, temperature, amount of sample, and extraction time, were optimised followed by a qualitative and semiquantitative analysis of the most abundant VOCs obtained under the optimum conditions.

\section{Experimental}

2.1. Sample Collection and Preparation. Mature seeds of $A$. danielli plant used in this study were collected from the Southern region of Nigeria. The collected seeds were crushed to powder $(\leq 0.5 \mathrm{~mm})$ using a quartz mortar and pestle.

\subsection{Sample Extraction Using HS-SPME. Different param-} eters amenable to headspace sampling were investigated, namely, temperature, amount of sample material used, and sampling time. SPME extraction was achieved using a $100 \mu \mathrm{m}$ polydimethylsiloxane solid phase microextraction (PDMS SPME) fibre, preconditioned for 30 minutes in a GC injection port at $200^{\circ} \mathrm{C}$. Different masses $(0.25,0.35$, and $0.50 \mathrm{~g})$ of the ground $A$. danielli seeds were introduced into a $2 \mathrm{~mL} \mathrm{GC}$ vial and the fibre was introduced $5 \mathrm{~mm}$ above the sample contained in the GC vial and incubated at set temperatures $\left(20,35,40\right.$, and $50^{\circ} \mathrm{C}$, resp.) in a water bath (Pierce, Rockford,
Illinois, USA) equipped with a multivial heating unit. The incubation period was varied between 10, 20, 30, 40, and 50 minutes. After each extraction time, the fibre was retracted into the needle and introduced into the GC injection port for desorption of analytes, chromatographic separation, and subsequent detection of VOCs via mass spectrometry. The different parameters, namely, temperature, mass of sample, and the extraction time, were optimised in a univariate manner. Each extraction and GC analysis were performed in triplicate $(n=3)$.

2.3. Annotation of Volatiles. Tentative annotation of the analytes was achieved through the mass comparisons of the mass spectra of individual compounds and compared with the NIST 2008, Wiley 2009, and Fragrances Libraries interfaced in the GCMS Solution Software running the instrument.

2.4. Instrumentation. Analysis of VOCs present in A. danielli seeds was performed using a Shimadzu QP 2010 gas chromatograph with mass spectrometer (Kyoto, Japan) fitted with a Restek Rtx-5ms (5\% phenyl-95\% dimethyl-polysiloxane) capillary column with the dimensions $30 \mathrm{~m} \times 0.25 \mathrm{~mm} \times$ $0.25 \mu \mathrm{m}$. The injection port temperature was set at $200^{\circ} \mathrm{C}$ and the optimised oven temperature programme began at $50^{\circ} \mathrm{C}$ held for 2 minutes, ramped to $170^{\circ} \mathrm{C}$ at a rate of $10^{\circ} \mathrm{C} /$ minutes, and then ramped to $250^{\circ} \mathrm{C}$ at a rate of $25^{\circ} \mathrm{C} /$ minutes and held for 2 minutes. Sample injection mode was splitless with a sampling time of 2 minutes followed by a split ratio of 1:10 using Helium (UHP Helium, Afrox, South Africa) as carrier gas pumped through the column at a constant flow rate of $1 \mathrm{~mL} /$ minute. The MS a transfer line temperature was set at $250^{\circ} \mathrm{C}$, and ion source temperature was $200^{\circ} \mathrm{C}$, with a scanning mode mass range of 50-500 amu.

\section{Results and Discussion}

3.1. Profiling and Annotation of Volatiles from the Seeds of A. danielli. Figure 1 shows the chromatogram of the extracted volatiles from the seeds of $A$. danielli using a headspace SPME with extraction conditions of $50^{\circ} \mathrm{C}, 0.25 \mathrm{~g}$ of sample, and 40 -minute extraction. The number annotations on the chromatogram indicates the peak indexes which correlates with their mass spectral data shown in Table 1.

It can be seen that peak (3) had the highest intensity followed by peak (2) and then peak (4). Peak (3) was annotated as eucalyptol (also known as 1,8-cineole) following confirmation on three libraries (NIST, Wiley, and Fragrances) all interfaced with the GCMS Solution software. However, a close inspection of this peak revealed that it could be composed of several compounds and not just one as shown by the small spikes at the apex of the peak as well as the different mass spectra detected at different positions of the same peak.

From Table 1 it can be seen that Wiley shows the highest match for all the compounds with NIST showing the lowest matches. However, the differences are only a few percentage points from one another. The listing of the compounds in the Flavour and Fragrances Library (FFRSC) indicates that such compounds have been used in the fragrances. Hence, 
TABLE 1: Some chromatographic data and tentative annotation of the top ten most abundant VOCs obtained from the headspace extraction of the ground $A$. danielli seeds.

\begin{tabular}{|c|c|c|c|c|c|c|c|c|}
\hline \multirow{2}{*}{ Peak } & \multirow{2}{*}{$\begin{array}{l}\text { Retention time } \\
\quad(\min )\end{array}$} & \multirow{2}{*}{$\begin{array}{l}\text { Compound } \\
\text { name }\end{array}$} & \multirow{2}{*}{ RMM } & \multirow{2}{*}{ Ref Ion } & \multirow{2}{*}{ Qual Ion } & \multicolumn{3}{|c|}{ Different library matches (\%) } \\
\hline & & & & & & NIST & FFSC & Wiley \\
\hline (1) & 5.087 & $\alpha$-Pinene & 136 & 93 & 77 & 96 & 96 & 97 \\
\hline (2) & 6.086 & $\beta$-Pinene & 136 & 93 & 69 & 96 & 96 & 97 \\
\hline (3) & 7.259 & Eucalyptol & 154 & 81 & 154 & 91 & 89 & 91 \\
\hline (4) & 10.082 & $\alpha$-Terpineol & 154 & 59 & 136 & 94 & 94 & 96 \\
\hline (5) & 12.434 & $\begin{array}{c}\alpha \text {-Terpinyl } \\
\text { acetate }\end{array}$ & 196 & 121 & 93 & 93 & 95 & 96 \\
\hline (6) & 13.515 & Bergamotene & 204 & 119 & 93 & 95 & 95 & 96 \\
\hline$(7)$ & 14.445 & $\beta$-Bisabolene & 204 & 69 & 93 & 90 & 95 & 96 \\
\hline
\end{tabular}

Key. RMM: relative molecular mass; Ref Ion: reference ion; Qual Ion: qualifier ion.

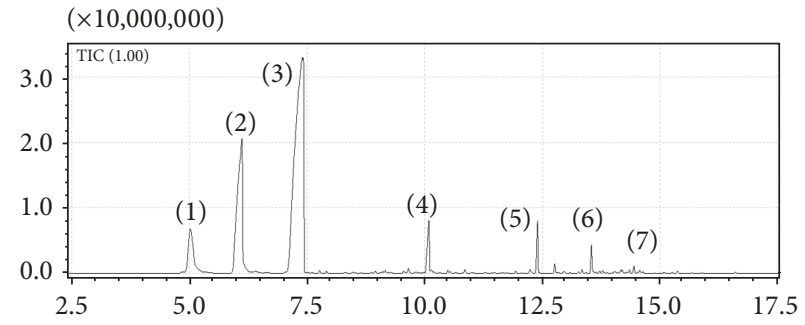

(a)

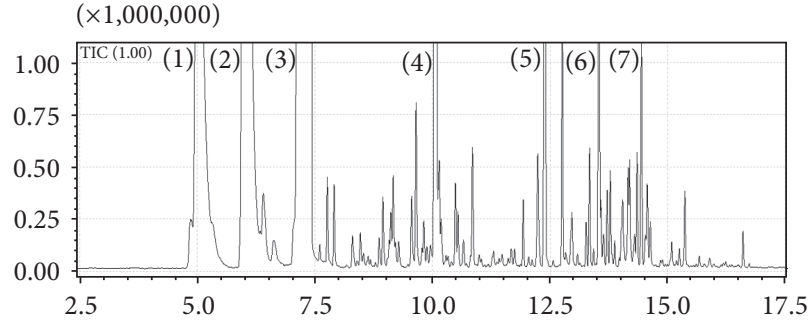

(b)

Figure 1: A chromatogram of the VOCs following a 40-minute extraction at $50^{\circ} \mathrm{C}$ : (a) depicts the chromatogram standardised against the largest peak (at about $7.5 \mathrm{~min}$ ) expanded to cover the region between 2.5 and 17.5 minutes while (b) depicts 10 times magnified chromatogram showing several tens of peaks that are not visible in (a) due to their low relative abundances compared to the seven peaks visible in (a).

this makes this plant a good candidate for use in fragrances industry.

\subsection{The Effect of Mass of the Sample on the Production and} Extraction of the VOCs. Logically the increase in the amount of sample should increase the production of the VOCs in a fixed unit volume. To optimise the mass of the sample required to yield the highest amount of the VOCs, different masses of the ground seeds were used and the amount of the VOCs produced is presented in Figure 2, plotted relative to $0.25 \mathrm{~g}$ sample for $n=3$ replicates.

As can be seen, the amount of the VOCs increased with the amount of the sample used. However, the increase is not linear as the data yielded the coefficient of determination, $R^{2} \leq 0.9126$ for terpinyl acetate although visually this was the most nonlinear curve (data not shown pictorially). The extraction seems to level off beyond $0.35 \mathrm{~g}$ of the sample while there is also a drop in repeatability as shown by the drop in relative standard deviations from the average of $7.7 \%$ for $0.25 \mathrm{~g}$ sample to $18.6 \%$ for $0.5 \mathrm{~g}$ samples, with the abundance of the VOCs increasing to an average of $134 \%$ using $0.5 \mathrm{~g}$ samples relative to $0.25 \mathrm{~g}$ samples. The compounds that resulted in the highest VOCs production (about 140\%) were $\alpha$-pinene and the two terpenoids while $\beta$-pinene and eucalyptol demonstrated the lowest increase (about 120\%). The levelling off could be attributed to the rate of uptake of the

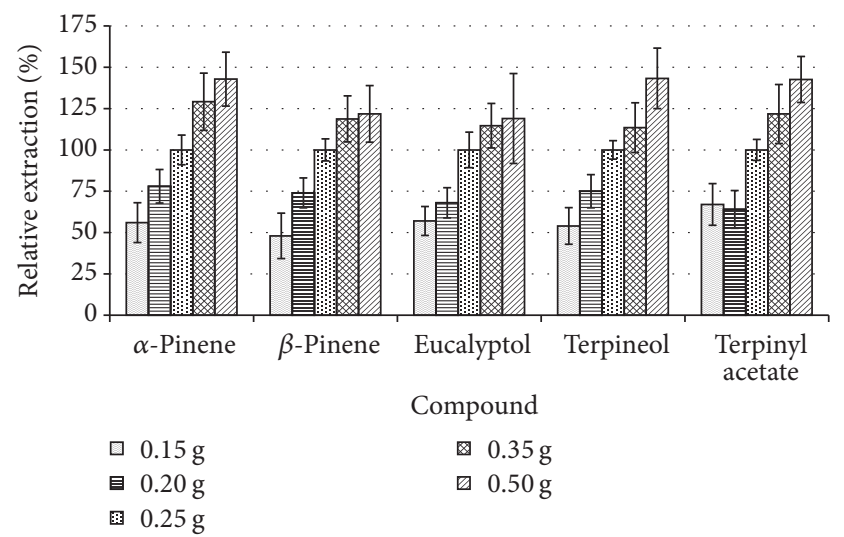

FIGURE 2: The effect of varying the amount of sample on the production of the VOCs.

analytes into the fibre which in this case becomes the limiting factor. Another factor could be the saturation of the fibre; however, this is unlikely since peak areas varied considerably. If this was due to saturation then the peak areas would be almost equal at all times. This, however, cannot be argued confidently given that the analysis was restricted to a few compounds (10, although only 5 are shown on the charts for ease of visualisation), yet from Figure 1 it can be seen that there are quite a number of compounds. 


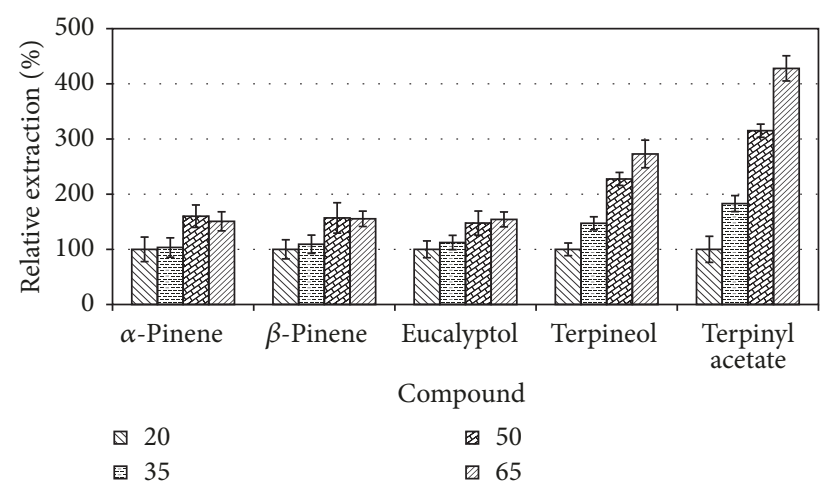

FIGURE 3: The effect of varying temperature on the extraction of volatiles from $A$. danielli seeds.

Another important aspect is the increase in the deviations as the amount of the sample was increased. This could be attributed to the reduced headspace volume that resulted in the fibre touching the sample rather than being suspended in the headspace, especially with the $0.5 \mathrm{~g}$ samples. This negates the benefit of increasing the amount of sample since the sample particles act as variable barriers for the passage of the analytes onto the fibre surface. This is so because the particle shape and size of the ground samples were not uniform, hence having different barriers at different times.

Due to the above factors, the amount of $0.25 \mathrm{~g}$ was selected as the most ideal sample amount and was used for further optimisation experiments.

3.3. The Effect of Temperature on Extraction Efficiency of Volatiles. Temperature is one of the most universal parameters that affect the efficiency of extraction through transfer of analytes to the headspace. Recently, a solvent-assisted headspace sampling was performed using organic solvents in driving analytes into the headspace; thus considerably reducing sampling time was reported albeit in aqueous matrices [25]. To assess the effect of temperature on extraction efficiency, samples in the GC-vials in this present study were incubated at different temperatures $\left(25-65^{\circ} \mathrm{C}\right)$ and extracted for a fixed period of 20 minutes.

Figure 3 shows the extraction efficiency relative to room temperature $\left(20^{\circ} \mathrm{C}\right)$ and only five compounds were shown for ease of visualisation chosen because of their abundance.

As can be seen in Figure 3, extraction efficiency of the VOCs increased 1.5-fold for the two pinene types and eucalyptol while those of terpineol and terpinyl acetate increased about 2.5 to 4.5 at $65^{\circ} \mathrm{C}$ compared to the $20^{\circ} \mathrm{C}$ (room temperature). The other interesting observation is that the latter two compounds showed the continued increase with temperature while the first three levelled off after $50^{\circ} \mathrm{C}$, after which time different behaviours were noticed. This is an indication of the dynamism of SPME extraction and the increased fluidity of the polymer with increase in temperature increasing the exchange of the analytes between the fibre and the headspace volume; therefore, $50^{\circ} \mathrm{C}$ was chosen for further extractions. Besides, the first three compounds eluting much earlier than the last two (terpineol and terpinyl acetate)

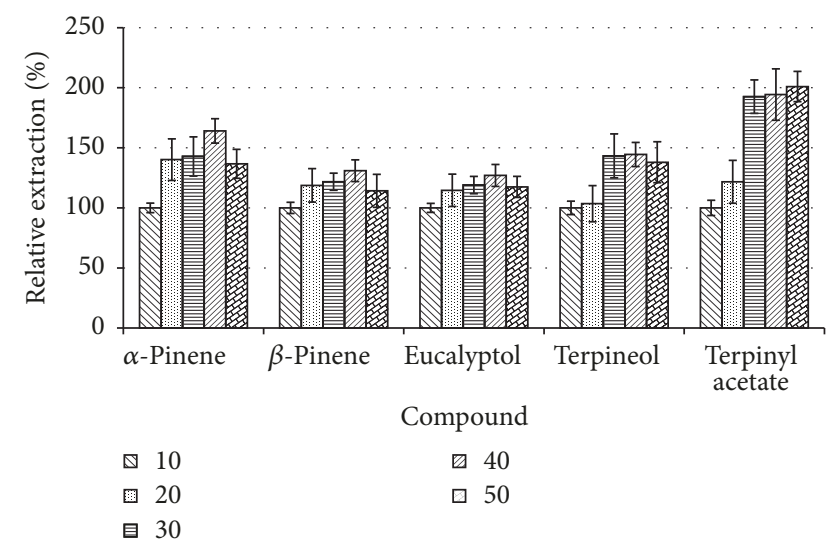

FIGURE 4: The effect of varying extraction time of volatiles of $A$. danielli.

indicated that their vapour pressure is much higher and they easily saturate the headspace. The latter compounds only enrich the headspace as the temperature is increased due to their relatively lower vapour pressure.

3.4. The Effect of Extraction Time on Extraction of the Volatiles. Given the solid nature and surface area of the fibre, SPME is characterised by slower extraction kinetics taking as long as one hour than its counterpart liquid-based methods such as single-drop microextraction that typically become saturated within about 20 minutes [26]. To assess the effect of temperature and the ideal time required for the highest extraction, different $0.25 \mathrm{~g}$ samples of $A$. danielli were incubated at $50^{\circ} \mathrm{C}$ and extracted after different time periods between 10 and 50 minutes. Figure 4 illustrates the effect of varying extraction times on the extraction of 5 most abundant volatiles recovered from the analysed spice.

As can be seen from Figure 4, the extraction of the lower volatile compounds seems to increase continuously with the increase in time (about twice that of 10-minute extraction time at 40 minutes), while for the most volatile compounds the extraction peaks and levels off at 40 minutes of extraction yielding about 1.25- to 1.75 -fold that of 10-minute extraction time at 40 minutes. This trend can still be explained by the dynamism of the fibre allowing the compounds to be exchanged between the fibre and the headspace volume as alluded to in the earlier section. However, the extraction time of 40 minutes was selected as the ideal time for the extraction of these VOCs from the crushed seeds.

3.5. Characterisation of the VOCs by Abundance and Comparison with Reported Literature on A. danielli and Other Plants. Following the optimised extraction time and temperature, a semiquantitative analysis was carried out on extracts obtained at optimal temperature of $50^{\circ} \mathrm{C}$ for 40 minutes. Table 2 provides a list of top 30 compounds selected on the basis of their relative abundance when extracted under optimised conditions as well as comparison with those reported in literature from the same plant (seeds, etc.). 
TABLE 2: Top 30 most abundant VOCs extracted from A. danielli seeds annotated using the three libraries listed in Table 1.

\begin{tabular}{|c|c|c|c|c|}
\hline $\begin{array}{l}\text { Retention time } \\
(\mathrm{min})\end{array}$ & $\begin{array}{l}\text { Percentage } \\
\text { abundance }\end{array}$ & Annotations* & $\begin{array}{l}\text { Literature reported } \\
\text { (Aframomum spp.) }\end{array}$ & $\begin{array}{c}\begin{array}{c}\text { Literature reported } \\
\text { (other plant species) }\end{array} \\
\end{array}$ \\
\hline 4.02 & 0.15 & $\alpha$-Thujene & {$[27,28]$} & \\
\hline 4.134 & 7.58 & $\alpha$-Pinene & {$[28,29]$} & \\
\hline 4.898 & 22.11 & $\beta$-Pinene oxide & & {$[30]$} \\
\hline 5.886 & 58.10 & Eucalyptol & [29] & \\
\hline 6.173 & 0.08 & $\gamma$-Terpinene & {$[31]$} & \\
\hline 6.294 & 0.09 & Sabinene hydrate $\langle E\rangle^{\delta}$ & {$[28,32]$} & \\
\hline 6.768 & 0.08 & Sabinene hydrate $\langle Z\rangle$ & {$[28]$} & \\
\hline 7.187 & 0.12 & $\alpha$-Campholenal & {$[31]$} & \\
\hline 7.388 & 0.39 & Pinocarveol $\langle Z\rangle$ & & {$[33]$} \\
\hline 7.743 & 0.11 & Pinocarvone & {$[28,34]$} & \\
\hline 7.823 & 0.28 & $\delta$-Terpineol & [31] & \\
\hline 7.976 & 0.11 & Terpinen-4-ol & {$[34]$} & \\
\hline 8.235 & 4.08 & $\alpha$-Terpineol & {$[28,34]$} & \\
\hline 8.594 & 0.21 & Carveol $\langle\mathrm{Z}\rangle$ & [28] & \\
\hline 8.941 & 0.18 & Carvone & [28] & \\
\hline 10.271 & 0.21 & Carvyl acetate $\langle Z\rangle$ & & [35] \\
\hline 10.419 & 1.83 & $\alpha$-Terpinyl acetate & [28] & \\
\hline 10.788 & 0.35 & $\alpha$-Copaene & {$[28,29]$} & \\
\hline 10.988 & 0.11 & $\beta$-Elemene & {$[28,36]$} & \\
\hline 11.359 & 0.12 & Caryophyllene $\langle(\mathrm{E})\rangle$ & & {$[37,38]$} \\
\hline 11.553 & 1.17 & $\alpha$-Bergamotene $\langle\mathrm{Z}\rangle$ & {$[34]$} & \\
\hline 11.73 & 0.09 & Valerena-4,7(11)-diene & & [39] \\
\hline 11.789 & 0.12 & $\beta$-Bergamotene $\langle\mathrm{E}\rangle$ & {$[28,32]$} & \\
\hline 12.05 & 0.15 & Aciphyllene $e^{\#}$ & & {$[40-42]$} \\
\hline 12.168 & 0.34 & Caryophyllene (Z) & & [38] \\
\hline 12.356 & 0.21 & Isodaucene & & {$[43]$} \\
\hline 12.446 & 0.31 & $\beta$-Bisabolene & {$[29,34]$} & \\
\hline 12.571 & 0.19 & $\beta$-Selinene & {$[29,34]$} & \\
\hline 13.365 & 0.13 & Caryophyllene oxide & {$[34]$} & \\
\hline 14.493 & 0.07 & $\alpha$-Bergamotol $\langle(\mathrm{Z}), \mathrm{E}\rangle$ & & {$[44]$} \\
\hline
\end{tabular}

* Annotation was made with the match of $\geq 85 \%$ from the NIST Library, with the lowest match of $85 \%$ obtained for the last three entries (sabinene hydrate $\langle\mathrm{E}\rangle$, $\gamma$-terpinene, and $\alpha$-bergamotol) with percentage abundances between 0.07 and $0.08 \% .{ }^{\delta}$ The $\mathrm{E}$ isomer has been reported elsewhere to elute earlier than the "Z" isomer [28, 32]. "Also reported in bacteria.

Clearly, it can be seen that the volatiles are dominated by compound depicted as peak (3) assigned as eucalyptol accounting for about $60 \%$ of the total peak areas for 30 peaks integrated automatically using autointegration software. This is followed by $\beta$-pinene oxide at $22 \%, \alpha$-pinene at $7.5 \%$, and terpineol at $4 \%$ as well as terpinyl acetate and bergamotene that accounted for about 2 and $1 \%$, respectively, with all the 26 remaining compounds, each with less than a percentage point collectively taking the remaining $6.5 \%$. However, it must be noted that the percentage indicated for each compound is relatively skewed due to the abundance of the first three compounds; most of these compounds are still significantly abundant as can be depicted in Figure 1.

\section{Conclusions}

The presented work demonstrated the effectiveness of the proposed method for screening the VOCs from the Aframomum danielli which in essence demonstrated the applicability to other plant seeds with rich content of volatile oils. In the current study, the amount of seeds material, time of extraction, and temperature of extraction were found to affect the outcomes of the extracted metabolites, both qualitatively and quantitatively. Thus, $0.25 \mathrm{~g}$ of finely ground ripe seeds, extraction time of 40 minutes, and a temperature of $50^{\circ} \mathrm{C}$ were found to be optimal for the extraction of the reported metabolites. Our results suggest that $A$. danielli seeds contain eucalyptol as a dominant VOC (about $60 \%$ of all the VOCs 
detected) with only six (6) compounds accounting for almost $95 \%$ of the total VOCs produced. Overall, A. danielli can be regarded as a potent source of eucalyptol oil; hence this plant can be used as a potent source for commercial production of this eucalyptol oil.

\section{Conflicts of Interest}

The authors declare that there are no conflicts of interest regarding the publication of this manuscript.

\section{Acknowledgments}

The authors gratefully acknowledge the University of Johannesburg for supporting this work. Mosotho J. George further acknowledges National University of Lesotho (RCC Grant P116-9008) and OPCW (Grant no. L/ICA/ICB/204905/16) for the research fellowship.

\section{References}

[1] G. O. Adegoke and A. G. Gopala Krishna, "Extraction and identification of antioxidants from the spice Aframomum danielli," Journal of the American Oil Chemists' Society, vol. 75, no. 8, pp. 1047-1052, 1998.

[2] S. O. Rotimi, O. A. Rotimi, T. Bisi-Adeniyi et al., "Gas chromatography mass spectrometry identification of antiangiogenic phytochemicals in Aframomum danielli K. Schum: An in silico study," International Journal of Pharmacognosy and Phytochemical Research, vol. 7, no. 6, pp. 1194-1201, 2015.

[3] M. O. Afolabi, G. O. Adegoke, and F. M. Mathooko, "Phytochemical characterization of the extracts of Aframomum danielli flower, leaf, stem and root," African Journal of Agricultural Research, vol. 6, no. 1, pp. 97-101, 2011.

[4] A. M. El-Halawany, R. S. E. Dine, N. S. El Sayed, and M. Hattori, "Protective effect of Aframomum melegueta phenolics against $\mathrm{CCl} 4$-induced rat hepatocytes damage; Role of apoptosis and pro-inflammatory cytokines inhibition," Scientific Reports, vol. 4, article no. 5880, 2014.

[5] G. O. Adegoke and B. J. Skura, "Nutritional profile and antimicrobial spectrum of the spice Aframomum danielli K. Schum," Plant Foods for Human Nutrition, vol. 45, no. 2, pp. 175-182, 1994.

[6] A. Dauda and G. Adegoke, "Preservation of Some PhysicoChemical Properties of Soymilk-Based Juice with Aframomum Danielli Spice Powder," American Journal of Food Science and Technology, vol. 2, no. 4, pp. 116-121, 2014.

[7] G. O. Babarinde, G. O. Adegoke, and R. Akinoso, "Effect of Aframomum danielli extract on some chemical and antioxidant components of roma tomato variety during storage," American Journal of Food Technology, vol. 9, no. 1, pp. 28-38, 2014.

[8] S. B. Fasoyiro and G. O. Adegoke, "Phytochemical characterization and the antimicrobial property of Aframomum danielli extract," African Journal of Agricultural Research, vol. 2, no. 3, pp. 76-79, 2007.

[9] I. A. Ajayi, I. O. Ademola, and S. V. Okotie, "Larvicidal effects of Aframomum danieli seed extracts against gastrointestinal nematode of sheep: in vitro studies," African Journal of Traditional, Complementary and Alternative Medicines, vol. 5, no. 3, pp. 244-246, 2008.
[10] M. O. Afolabi and G. O. Adegoke, "Antioxidative and flavouring effects of Aframomum danielli on biscuits," African Journal of Food Science, vol. 8, no. 4, pp. 200-203, 2014.

[11] F. R. Irvine, “The Useful Plants of West Tropical Africa. By J. D. Dalziel, M.D., B.Sc, F.L.S. Being an Appendix to The Flora of West Tropical Africa, by Hutchinson and Dalziel. London: Crown Agents for the Colonies. 1937. Pp. 612. 18s.," Africa, vol. 11, no. 02, pp. 254-255, 1938.

[12] M. D’Alessandro and T. C. J. Turlings, "Advances and challenges in the identification of volatiles that mediate interactions among plants and arthropods," Analyst, vol. 131, no. 1, pp. 24-32, 2006.

[13] J. Kesselmeier and M. Staudt, "Biogenic volatile organic compounds (VOC): an overview on emission, physiology and ecology," Journal of Atmospheric Chemistry, vol. 33, no. 1, pp. 23$88,1999$.

[14] A. C. Steinemann, I. C. MacGregor, S. M. Gordon et al., "Fragranced consumer products: Chemicals emitted, ingredients unlisted," Environmental Impact Assessment Review, vol. 31, no. 3, pp. 328-333, 2011.

[15] R. Gyawali and K. S. Kim, "Volatile organic compounds of medicinal values from Nepalese Acorus calamus L, Kathmandu University Journal of Science," Journal of Engineering and Technology, vol. 5, no. 2, pp. 51-65, 2009.

[16] F. Manzoor, S. A. Malik, N. Naz, K. J. Cheema, and S. Naz, "Potential of antitermitic activities of eucalyptus oil," Pakistan Journal Of Zoology, vol. 44, no. 2, pp. 335-339, 2012.

[17] E. Ormeño, A. Goldstein, and Ü. Niinemets, "Extracting and trapping biogenic volatile organic compounds stored in plant species," TrAC - Trends in Analytical Chemistry, vol. 30, no. 7, pp. 978-989, 2011.

[18] D. Tholl, W. Boland, A. Hansel, F. Loreto, U. S. R. Röse, and J.-P. Schnitzler, "Practical approaches to plant volatile analysis," The Plant Journal, vol. 45, no. 4, pp. 540-560, 2006.

[19] C. C. Teo, S. N. Tan, J. W. H. Yong, C. S. Hew, and E. S. Ong, "Pressurized hot water extraction (PHWE)," Journal of Chromatography A, vol. 1217, no. 16, pp. 2484-2494, 2010.

[20] C. Bicchi, C. Cordero, E. Liberto, B. Sgorbini, and P. Rubiolo, "Headspace sampling of the volatile fraction of vegetable matrices," Journal of Chromatography A, vol. 1184, no. 1-2, pp. 220-233, 2008.

[21] M. Kusano, M. Kobayashi, Y. Iizuka, A. Fukushima, and K. Saito, "Unbiased profiling of volatile organic compounds in the headspace of Allium plants using an in-tube extraction device," BMC Research Notes, vol. 9, no. 1, article no. 133, 2016.

[22] D. Materić, D. Bruhn, C. Turner, G. Morgan, N. Mason, and V. Gauci, "Methods in plant foliar volatile organic compounds research," Applications in Plant Sciences, vol. 3, no. 12, 2015.

[23] N. P. Brunton, D. A. Cronin, F. J. Monahan, and R. Durcan, "A comparison of solid-phase microextraction (SPME) fibres for measurement of hexanal and pentanal in cooked turkey," Food Chemistry, vol. 68, no. 3, pp. 339-345, 2000.

[24] Q. L. Ma, N. Hamid, A. E. D. Bekhit, J. Robertson, and T. F. Law, "Optimization of headspace solid phase microextraction (HSSPME) for gas chromatography mass spectrometry (GC-MS) analysis of aroma compounds in cooked beef using response surface methodology," Microchemical Journal, vol. 111, pp. 1624, 2013.

[25] M. J. George, L. Marjanovic, and D. B. G. Williams, "SolventAssisted Headspace Sampling Using Solid Phase Microextraction for the Analysis of Phenols in Water," Analytical Chemistry, vol. 87, no. 19, pp. 9559-9562, 2015. 
[26] D. B. G. Williams, M. J. George, R. Meyer, and L. Marjanovic, "Bubbles in solvent microextraction: The influence of intentionally introduced bubbles on extraction efficiency," Analytical Chemistry, vol. 83, no. 17, pp. 6713-6716, 2011.

[27] A. C. Ngakegni-Limbili, B. Zebib, M. Cerny et al., "Aframomum stipulatum (gagnep) k. schum and aframomum giganteum (oliv. \& hanb) k. schum as aroma tincto oleo crops resources: Essential oil, fatty acids, sterols, tocopherols, and tocotrienols composition of different fruit parts of congo varieties," Journal of the Science of Food and Agriculture, vol. 93, no. 1, pp. 67-75, 2013.

[28] G. O. Adegoke, L. Jagan Mohan Rao, and N. B. Shankaracharya, "A comparison of the essential oils of Aframomum daniellii (Hook, f.) K, Schum, and Amomum subulatum Roxb," Flavour and Fragrance Journal, vol. 13, no. 5, pp. 349-352, 1998.

[29] G. D. Diomandé, A. M. Koffi, Z. F. Tonzibo, G. Bedi, and G. Figueredo, "GC and GC/MS analysis of essential oil of five Aframomum species from Côte Divoire," Middle-East Journal of Scientific Research, vol. 11, no. 6, pp. 808-813, 2012.

[30] E. Salminen, P. Mäki-Arvela, P. Virtanen, T. Salmi, J. Wärnå, and J.-P. Mikkola, "Kinetics upon isomerization of $\alpha, \beta$-pinene oxides over supported ionic liquid catalysts containing lewis acids," Industrial \& Engineering Chemistry Research, vol. 53, no. 52, pp. 20107-20115, 2014.

[31] M. A. Couppé de K. Martin, H. Joseph, S. Bercion, and C. Menut, "Chemical composition of essential oils from aerial parts of Aframomum exscapum (Sims) Hepper collected in Guadeloupe, French West Indies," Flavour and Fragrance Journal, vol. 21, no. 6, pp. 902-905, 2006.

[32] P. H. Amvam Zollo, R. Abondo, L. Biyiti, C. Menut, and J. M. Bessière, "Aromatic plants of Tropical Central Africa XXXVIII: Chemical composition of the essential oils from four Aframomum species collected in Cameroon (1)," Journal of Essential Oil Research, vol. 14, no. 2, pp. 95-98, 2002.

[33] M. Couladis, V. Tsortanidou, J. Francisco-Ortega, A. SantosGuerra, and C. Harvala, "Composition of the essential oils of Argyranthemum species growing in the Canary Islands," Flavour and Fragrance Journal, vol. 16, no. 2, pp. 103-106, 2001.

[34] E. Adjalian, F. T. D. Bothon, B. Yehouenou et al., "GC/MS and GC/FID analysis and evaluation of antimicrobial performance of Aframomum sceptrumessential oils of Benin," World Journal of Pharmaceutical Sciences, vol. 2, no. 8, pp. 787-792, 2014.

[35] A. Nezhadali and M. Parsa, "Study of the Volatile Compounds in Artemisia Sagebrush from Iran using HS/SPME/GC/MS," International Journal of Environmental Science and Development, pp. 287-289, 2010.

[36] S. Eyob, M. Appelgren, J. Rohloff, A. Tsegaye, and G. Messele, "Traditional medicinal uses and essential oil composition of leaves and rhizomes of korarima (Aframomum corrorima (Braun) P.C.M. Jansen) from southern Ethiopia," South African Journal of Botany, vol. 74, no. 2, pp. 181-185, 2008.

[37] L. C. Salanta, M. Tofana, S. A. Socaci, C. L. Pop, D. Michiu, and A. Farcas, "Determination of the volatile compounds from hop and hop products using ITEX/GC-MS technique," Journal of Agroalimentary Processes and Technologies, vol.18, no. 2, pp.110115, 2012.

[38] S. Oluwafemi, T. J. Bruce, J. A. Pickett, J. Ton, and M. A. Birkett, "Behavioral Responses of the Leafhopper, Cicadulina storeyi China, a Major Vector of Maize Streak Virus, to Volatile Cues from Intact and Leafhopper-Damaged Maize," Journal of Chemical Ecology, vol. 37, no. 1, pp. 40-48, 2011.
[39] B. W. Pyle, H. T. Tran, B. Pickel et al., "Enzymatic synthesis of valerena-4,7(11)-diene by a unique sesquiterpene synthase from the valerian plant (Valeriana officinalis)," FEBS Journal, vol. 279, no. 17, pp. 3136-3146, 2012.

[40] T. Nawrath, G. F. Mgode, B. Weetjens, S. H. E. Kaufmann, and S. Schulz, "The volatiles of pathogenic and nonpathogenic mycobacteria and related bacteria," Beilstein Journal of Organic Chemistry, vol. 8, pp. 290-299, 2012.

[41] C. M. Buré and N. M. Sellier, "analysis of the essential oil of indonesian patchouli (pogostemon cabin benth.) using GC/MS (EI/CI)," Journal of Essential Oil Research, vol. 16, no. 1, pp. 17-19, 2004.

[42] M. A. Hossain, M. J. Kabir, S. M. Salehuddin et al., "Antibacterial properties of essential oils and methanol extracts of sweet basil Ocimum basilicum occurring in Bangladesh," Pharmaceutical Biology, vol. 48, no. 5, pp. 504-511, 2010.

[43] V. Mazzoni, F. Tomi, and J. Casanova, "A daucane-type sesquiterpene from Daucus carota seed oil," Flavour and Fragrance Journal, vol. 14, no. 5, pp. 268-272, 1999.

[44] L. Jirovetz, G. Buchbauer, M. P. Shafi, and M. M. Kaniampady, "Chemotaxonomical analysis of the essential oil aroma compounds of four different Ocimum species from southern India," European Food Research and Technology, vol. 217, no. 2, pp. 120124, 2003. 

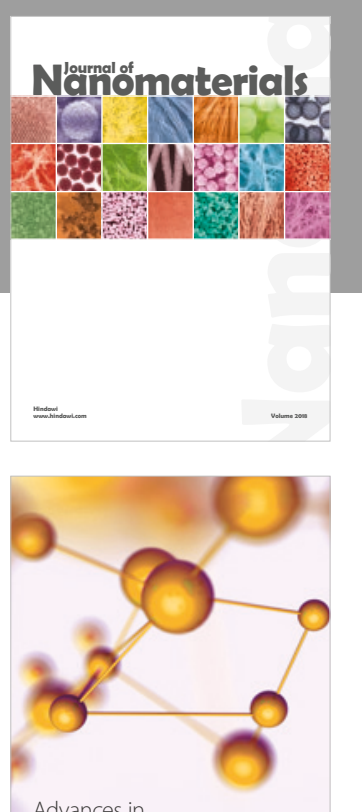

Physical Chemistry
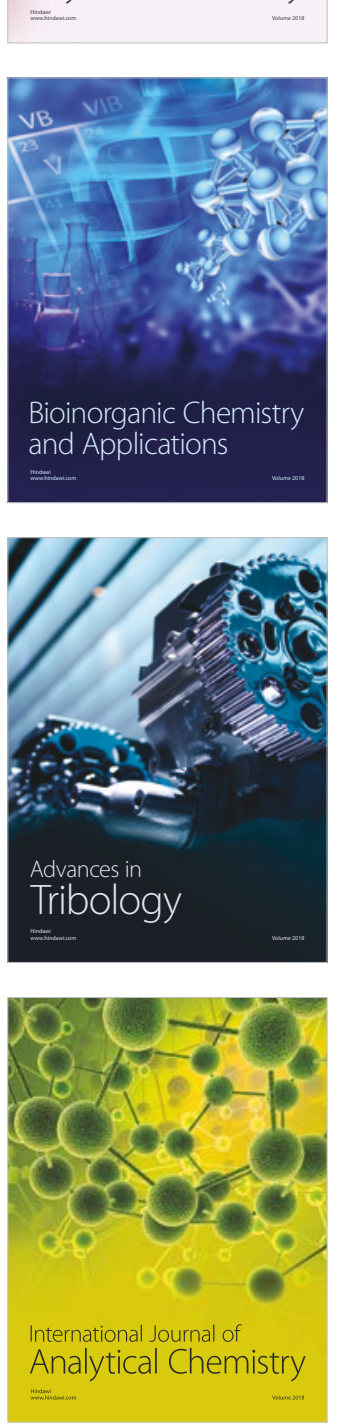

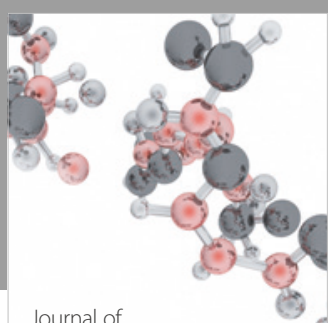

Analytical Methods

in Chemistry

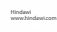

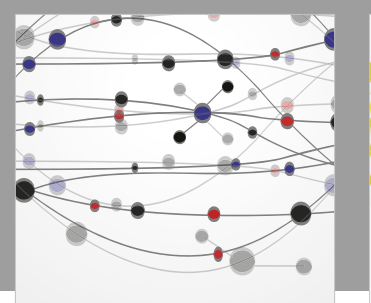

The Scientific World Journal

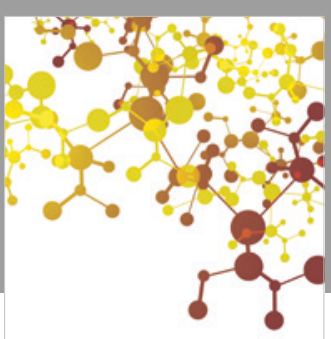

Journal of

Applied Chemistry
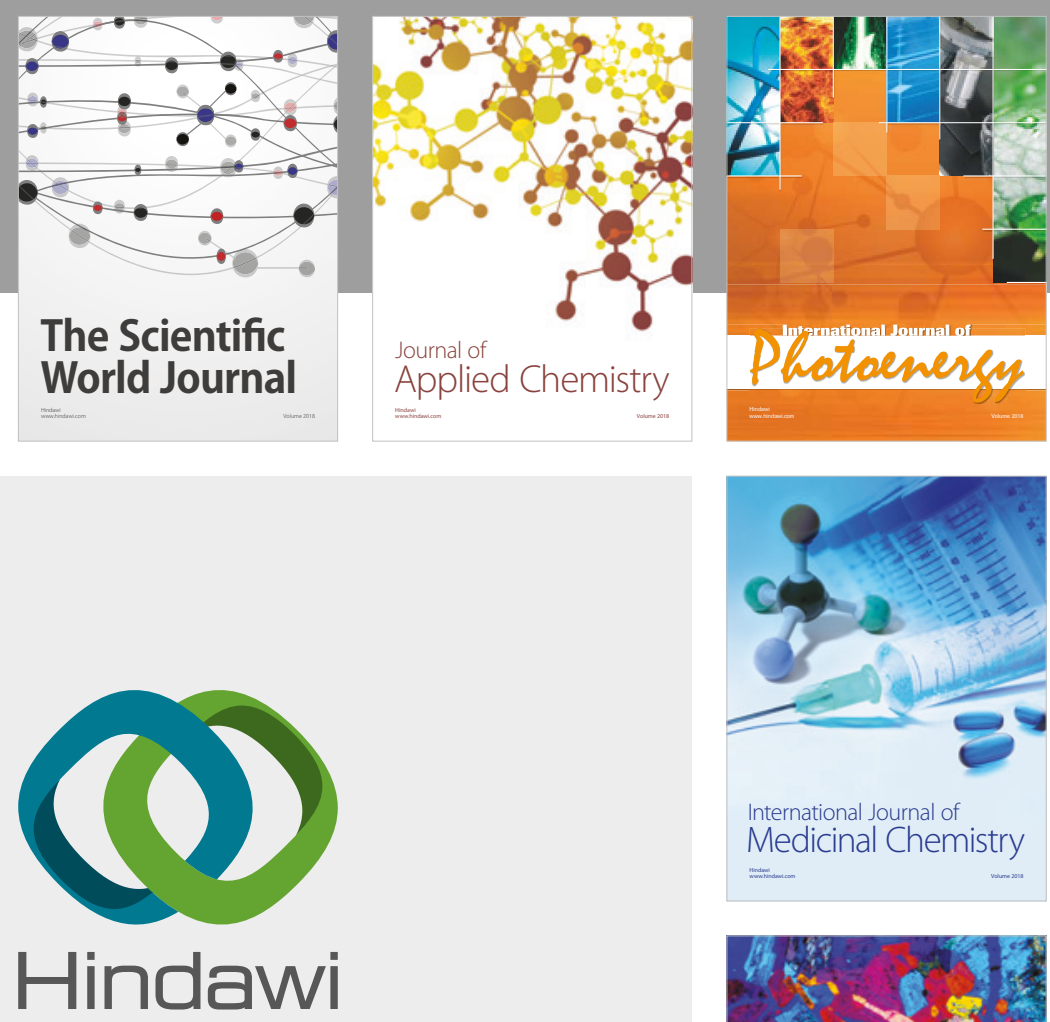

Submit your manuscripts at

www.hindawi.com
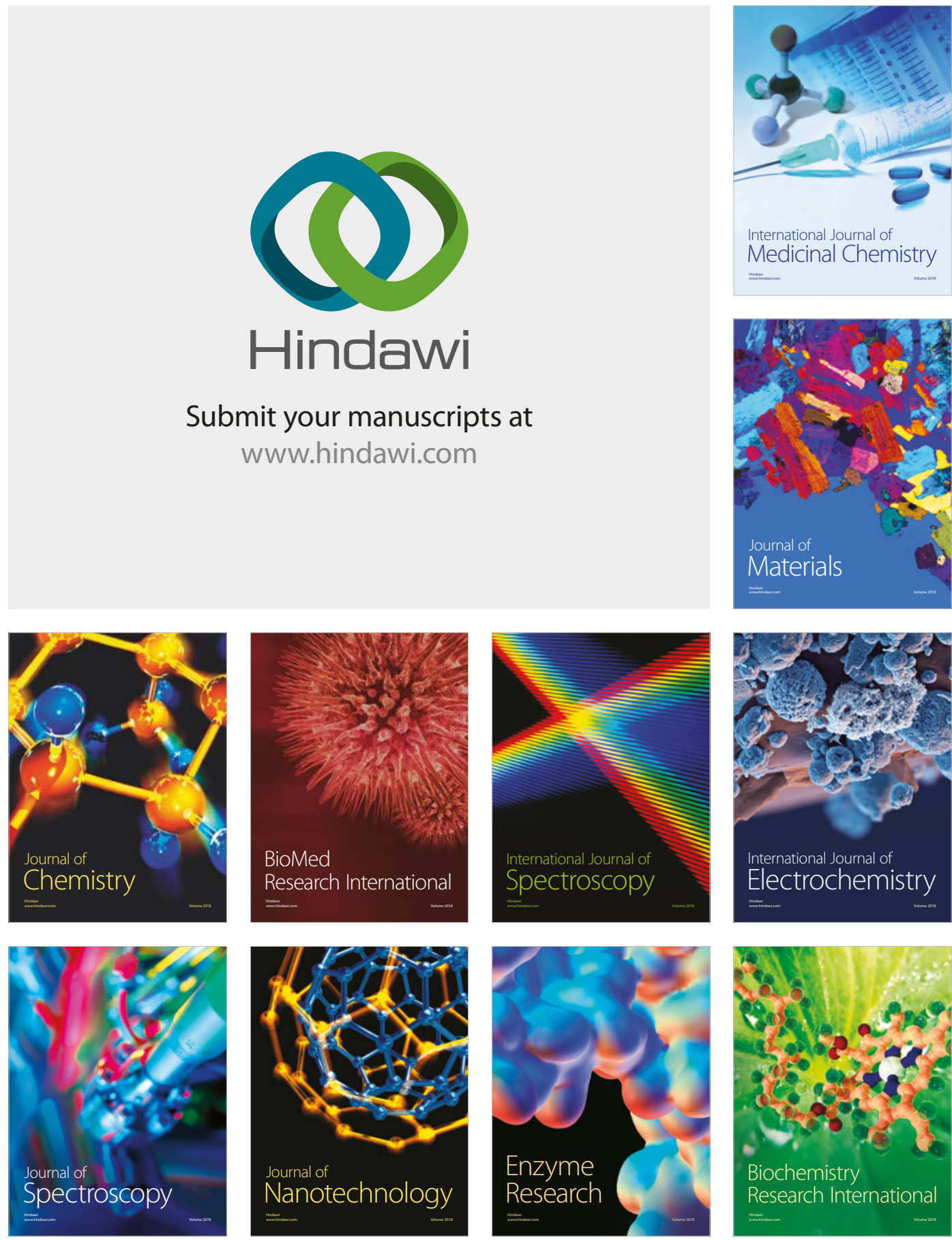
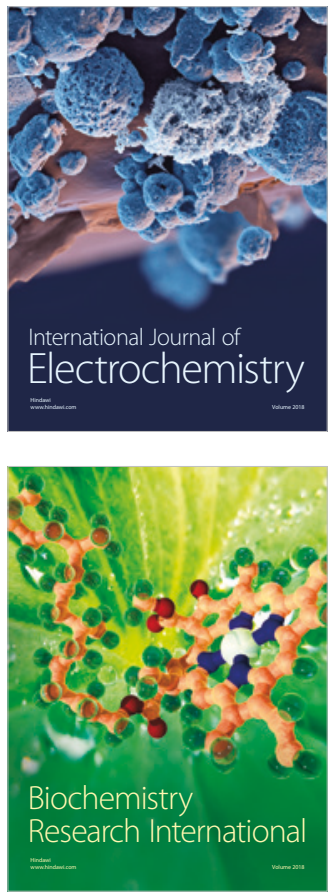